\title{
Five-year follow-up results of aerobic and impact training on bone mineral density in early breast cancer patients
}

\author{
L. Vehmanen ${ }^{1}(1) \cdot$ H. Sievänen ${ }^{2} \cdot$ P. Kellokumpu-Lehtinen ${ }^{3} \cdot$ R. Nikander ${ }^{4} \cdot$ R. Huovinen ${ }^{5} \cdot$ J. Ruohola $^{5}$. \\ H.M. Penttinen ${ }^{6} \cdot$ M. Utriainen ${ }^{1} \cdot$ K. Tokola $^{2} \cdot$ C. Blomqvist $^{1,7} \cdot$ T. Saarto $^{1}$
}

Received: 7 January 2020 / Accepted: 25 August 2020 / Published online: 4 September 2020

(C) The Author(s) 2020

\begin{abstract}
Summary A 12-month exercise program reversibly prevented hip bone loss in premenopausal women with early breast cancer. The bone-protective effect was maintained for 2 years after the end of the program but was lost thereafter.

Purpose Breast cancer survivors are at an increased risk for osteoporosis and fracture. This 5 -year follow-up of a randomized impact exercise intervention trial evaluated the maintenance of training effects on bone among breast cancer patients.

Methods Five hundred seventy-three early breast cancer patients aged 35-68 years and treated with adjuvant therapy were allocated into a 12-month exercise program or a control group. Four hundred forty-four patients (77\%) were included in the 5year analysis. The exercise intervention comprised weekly supervised step aerobics, circuit exercises, and home training. Areal bone mineral density (aBMD) was measured by dual-energy X-ray absorptiometry. Physical activity was estimated in metabolic equivalent (MET) hours per week and physical performance assessed by $2-\mathrm{km}$ walking and figure- 8 running tests .

Results In premenopausal patients, the 12-month exercise program maintained femoral neck (FN) and total hip (TH) aBMD for 3 years, but the protective effect was lost thereafter. The mean FN aBMD change in the exercise and control groups was $-0.2 \%$ and $-1.5 \% 1$ year, $-1.1 \%$ and $-2.1 \% 3$ years and $-3.3 \%$ versus $-2.4 \% 5$ years after the beginning of the intervention, respectively. Lumbar spine (LS) bone loss was not prevented in premenopausal women and no training effects on aBMD were seen in postmenopausal women. The main confounding element of the study was the unexpected rise in physical activity among patients in the control group. The physical performance improved among premenopausal women in the exercise group compared with the controls.
\end{abstract}

Conclusion The 12-month exercise program prevented FN and TH bone loss in premenopausal breast cancer patients for 3 years. The bone-protective effect was reversible and lost thereafter.

Keywords Bone density $\cdot$ Breast cancer $\cdot$ Weight-bearing impact aerobic exercise $\cdot$ Training $\cdot$ Osteoporosis $\cdot$ Physical activity

All authors have contributed to the study.

Electronic supplementary material The online version of this article (https://doi.org/10.1007/s00198-020-05611-w) contains supplementary material, which is available to authorized users.

L. Vehmanen

leena.vehmanen@hus.fi

1 Department of Oncology, Helsinki University Central Hospital, Comprehensive Cancer Center and University of Helsinki, Helsinki, Finland

2 The UKK Institute for Health Promotion Research, Tampere, Finland

3 Department of Oncology, Faculty of Medicine, Tampere University Central Hospital, University of Tampere, Tampere, Finland
4 Department of Sport and Health Sciences, University of Jyväskylä, Jyväskylä, Finland

5 Department of Oncology, Turku University Central Hospital, Turku, Finland

6 Cancer Society of Pirkanmaa, Tampere, Finland

7 Department of Oncology, Örebro University Hospital, Örebro, Sweden 


\section{Introduction}

Breast cancer is the most commonly occurring malignancy in women. Systemic breast cancer therapies interfere with bone turnover and predispose patients to cancer treatment-related bone loss [1]. Breast cancer survivors are at an increased risk for osteoporosis and fracture compared with women in general [2].

Chemotherapy causes premature menopause in most premenopausal women aged 40 years or more [3, 4]. Estrogen deficiency due to early menopause disturbs bone remodeling and leads to accelerated bone loss. Endocrine therapy with aromatase inhibitors inhibits peripheral estrogen production in postmenopausal women, and suppressed estrogen levels lead to increased bone loss and risk of fracture $[1,5]$.

Bisphosphonates and denosumab prevent cancer treatmentrelated bone loss [1,6]. A recent meta-analysis suggested that bisphosphonates also reduce the risk of bone metastasis and breast cancer death among postmenopausal, but not premenopausal women. Reasons for this difference are not fully understood, but bisphosphonates seem to have antitumoral activity only in estrogen-deficient bone microenvironment $[1,6,7]$.

While exercise too may reduce bone loss, it also helps to overcome many other treatment-related adverse effects like fatigue and psychological symptoms and improves the quality of life $[8,9]$. Exercise seems to have a positive effect on breast cancer prognosis as well. Moderate-intensity physical activity has been related to decreased breast cancer mortality in a few studies [10].

High-intensity resistance and weight-bearing training have been shown to reduce bone loss in healthy pre- and postmenopausal women [11-14]. Much less is known about the skeletal benefits of exercise among breast cancer survivors, but a few exercise intervention studies have been carried out with varying results [15-24]. To our knowledge, the current BREX (Breast Cancer and Exercise) study is the largest prospective exercise intervention study on breast cancer survivors.

We have previously shown that a 12-month combined impact and aerobic exercise program prevents FN bone loss during the intervention in premenopausal women with early breast cancer. No exercise effect was found at LS or in postmenopausal women [24]. The aim of this 5-year follow-up of a randomized clinical trial was to evaluate the long-term effect of weight-bearing jumping exercises and circuit training on bone loss among breast cancer patients.

\section{Patients}

The BREX study is an open, randomized controlled exercise intervention trial. A total of 573 pre- and postmenopausal women aged from 35 to 68 years with newly diagnosed breast cancer enrolled into the study between September 2005 and September 2007 from the Departments of Oncology in Helsinki, Tampere, and Turku University Hospitals, Finland.
Inclusion and exclusion criteria and flowchart of the study patients are presented in the Electronic Supplementary Material. Patients were randomly allocated into 1-year exercise training or control groups. Randomization was centralized and stratified for study centers, menopausal status, endocrine treatment in postmenopausal women (aromatase inhibitor vs. tamoxifen vs. no endocrine treatment), and for age in premenopausal women (below or above 45 years).

The local ethical committee of Helsinki University Hospital approved the study protocol. Informed consent was obtained from all individual participants included in the study. The trial was registered in the Helsinki and Uusimaa Hospital District Clinical Trials Register (www.hus.fi; 210590) and in the http:// www.clinicaltrials.gov/; NCT00639210).

All patients were treated with adjuvant chemotherapy and/ or endocrine therapy. Radiotherapy was given after breastconserving surgery. Radiation to the chest wall after mastectomy and regional nodal irradiation was given according to local clinical guidelines. Chemotherapy and radiotherapy had to be completed and endocrine treatment started no later than 4 months before study enrollment.

Three different chemotherapy regimens at 3-week intervals were used: six cycles of FEC (5-fluorouracil, epirubicin, and cyclophosphamide), three cycles of docetaxel followed by three cycles of FEC or three cycles of docetaxel followed by three cycles of EC (epirubicin and cyclophosphamide), both of the last two regimens combined with capecitabine for 2 weeks. The recommended endocrine treatment was tamoxifen for premenopausal patients and aromatase inhibitor, tamoxifen, or both sequentially for postmenopausal patients.

Of the 573 randomized patients, 537 (94\%) received the allocated intervention (284 in the exercise and 253 in the control group). Ninety-three patients were excluded from the 5year analyses due to breast cancer recurrence (51 patients), study discontinuation (27 patients), new malignancy (11 patients), or other reasons (4 patients). Altogether, 444 (77\%) were included in the 5-year analyses. Of these women, 201 were premenopausal and 243 postmenopausal.

The division into pre- and postmenopausal groups was based on the baseline menstrual status of the patients. The definition of postmenopausal status was at least 12 months of amenorrhea and for those, whose menstruation status could not be assessed due to hysterectomy or hormonal IUD, patients $<50$ years were classified as premenopausal, patients $\geq 55$ years as postmenopausal, and those in between according to whether FSH was in the postmenopausal range (>30 IU/l) or not. Most of the patients went through menopause during the study follow-up period of 5 years.

\section{Exercise intervention}

The total duration of the exercise training program was 12 months, and it comprised supervised exercise and home 
training. The exercise group attended either one 60-min supervised session of step aerobics (including 150 to 180 jumps or leaps) or circuit training (including 150-180 steps and hops) on alternate weeks and three home training sessions per week. The training was progressive. A detailed description of the exercise sessions has been published previously [24]. Patients in the control group were recommended to maintain their usual level of physical activity and exercise habits.

Compliance to the 12-month exercise program was satisfactory both among the premenopausal and postmenopausal women. The premenopausal women in the exercise group $(n=107)$ attended a median 30 of the 52 supervised training sessions (58\%). According to training diaries, home training was done on average 2.8 times a week ( $93 \%$ of recommended). The mean weekly number of steps or jumps was 160 (53\%) during home training. The median total number of supervised and home training sessions together was 3.3 times per week (IQR, 2.4 4.6). The postmenopausal women in the exercise group $(n=128)$ attended a median 33 of the 52 supervised sessions (63\%). According to training diaries, home training was done on average 3.2 times (107\%) a week. The number of weekly steps or jumps was 206 (69\%). The median total number of training sessions was 4.3 times per week (IQR, 2.3-5.4) [24].

\section{Physical activity}

The type, extent, and intensity of leisure time physical activity before and after breast cancer diagnosis was assessed via a questionnaire and classified as low, moderate, hard, or very hard intensity. Information on the intensity of physical activity was collected by means of a prospective 2-week physical activity diary. Patients filled the diary before the beginning of the intervention, every 6 months until 3 years and thereafter at 5 years. Activity was categorized as light ( $<$ three METs), moderate (three to six METs), vigorous (six to nine METs), or hard intensity (> nine METs). One MET denotes the amount of oxygen consumed at rest in supine position and matches $3.5 \mathrm{ml}$ oxygen consumption per kilogram each minute [25].

The total physical activity was expressed in MET-hours per week (MET-h/week) and calculated by multiplying the intensity of the activity by the time spent. MET-hours per week were also analyzed separately for moderate- to hard-intensity (three to nine METs or above) exercise training. In addition, the time spent in supervised and home trainings and the sum of jumps during home training were collected using a questionnaire.

\section{Physical performance and bone mineral density}

Measurements of physical performance, body composition, and aBMD were done at baseline, after completion of the 12-month intervention and at 3 and 5 years thereafter. The researchers were not involved in training of the participants and were kept blinded to the patients' group allocation, whereas patients were requested not to reveal their study group during the tests.

Cardiorespiratory fitness was tested by asking the participants to walk a level $2-\mathrm{km}$ distance as quickly as possible and measuring the corresponding walking time (UKK walking test, Tampere, Finland) [26]. Dynamic neuromuscular performance was evaluated by the figure- 8 running test [27]. The test is done by running two loops around a track including two poles $10 \mathrm{~m}$ apart.

Body height and weight were measured using standard methods. aBMD $\left(\mathrm{g} / \mathrm{cm}^{2}\right)$ was measured by dual-energy Xray absorptiometry (DXA) at LS (vertebrae L1-L4), left femoral neck (FN), and the total hip (TH). The reproducibility and coefficients of variation $(\mathrm{CV})$ for each of the tests above were presented in our previous publication [24].

In Helsinki, aBMD was measured with Hologic Discovery A and in Tampere, with Lunar Prodigy Advance, at baseline and during follow-up. In Turku, Hologic QDR-4500 was used at baseline and either Hologic QDR-4500, Medilink Osteocore III, or Medilink Medix during follow-up. Since different DXA brands were employed and their aBMD values may not be directly commensurable, the baseline DXA results are reported separately for each center, and only the absolute changes in aBMD data were compared.

\section{Clinical investigations}

Staging investigations were performed before adjuvant treatments. Clinical investigations, including basic laboratory safety tests and radiological examinations, were repeated according to local routine follow-up practice. Medical history and clinical examination were done at baseline, after completion of the 12-month intervention and at 3 and 5 years thereafter. Self-reports of clinically apparent fragility fractures were collected at each visit. Fractures in metacarpals, metatarsals, fingers, toes, skull, and nasal bones were excluded as nonfragility fractures. The patients filled in a questionnaire covering basic demographics, lifestyle issues, and a 2-week exercise diary before the intervention and every 6 months until 3 years and finally at 5 years.

\section{Statistical analysis}

The a priori power calculation indicated that 400 patients would have been sufficient for testing the pre- and postmenopausal women separately and with multiple-test adjustment.

Data were analyzed longitudinally (four time points: baseline, 1 year, 3 years, and 5 years) with linear mixed models 
(LMM). Endocrine therapy and baseline values of age and weight were used as covariates. For premenopausal patients, menopause status was also included in the models as a longitudinal covariate. A sensitivity test including Met-h/week at baseline was done and did not change the results. Cox proportional hazards regression models were used to calculate hazard ratios for fractures. Changes between two time points were presented with mean difference and $95 \%$ confidence interval. All the analyses were performed using IBM SPSS software (version 24, IBM Corp, Armonk, NY, USA).

\section{Results}

The final study population encompassed 235 patients in the exercise group (107 premenopausal and 128 postmenopausal) and 209 patients in the control group (94 premenopausal and 115 postmenopausal). Around $90 \%$ of both pre- and postmenopausal women had received adjuvant chemotherapy. The baseline group characteristics are presented in Table 1.

\section{Effect of the exercise intervention on aBMD changes during the follow-up}

\section{Premenopausal patients}

aBMD changes at the FN during follow-up differed significantly between the exercise and control groups ( $p=0.015)$. The 12-month exercise program prevented FN bone loss during the intervention and the effect was maintained for 2 years thereafter. Only marginal bone loss $-0.2 \%$ at the FN was noted among women in the exercise group, while women in the control group lost $-1.5 \%$ during the first 12 months. The protective effect of exercise was reversible and gradually lost during further follow-up, as the bone loss was $-1.1 \%$ and $2.1 \%$ at 3 years but $-3.3 \%$ versus $-2.4 \%$ at 5 years in the exercise and control groups, respectively (Fig. 1a).

The $\mathrm{TH}$ aBMD changes resembled those of the $\mathrm{FN}$, and similarly, a significant difference between the exercise and control groups emerged $(p=0.004)$. The bone loss at the $\mathrm{TH}$ was $-0.2 \%$ in the exercise group and $-1.2 \%$ in the controls during the first 12 months, $-0.3 \%$ and $-1.6 \%$ at 3 years and $-2.2 \%$ and $-1.5 \%$ at 5 years, respectively.

The exercise intervention had no significant effect on the LS aBMD changes $(p=0.959)$. The baseline LS aBMD in the exercise group was lower than in the control group. The LS aBMD decreased $-1.9 \%$ among women in the exercise group and $-2.4 \%$ in the controls during the first 12 months. The bone loss was $-3.2 \%$ and $-3.2 \%$ at 3 years and $-5.1 \%$ versus $-4.7 \%$ at 5 years in the exercise and control groups, respectively (Fig. 1b).

\section{Postmenopausal patients}

The exercise intervention had no significant effect on the FN aBMD changes $(p=0.395)$. The FN aBMD decreased $-1.2 \%$ in the exercise group and $-1.4 \%$ in the control group during the 12 -month intervention, -1.8 and $-1.7 \%$ at 3 years and $3.9 \%$ versus $-3.2 \%$ at 5 years, respectively (Fig. 1a).

The TH aBMD changes did not differ between the exercise and control groups $(p=0.989)$. The bone loss at the TH was $1.2 \%$ in the exercise group and $-1.5 \%$ in the controls during the first 12 months, $-1.0 \%$ and $-1.5 \%$ at 3 years and $-2.9 \%$ and $-2.7 \%$ at 5 years, respectively.

The exercise intervention had no significant effect on the LS aBMD $(p=0.213)$ The LS aBMD declined $-1.4 \%$ in the exercise and $-2.2 \%$ in the control group during the 12-month period, $-2.3 \%$ and $-3.1 \%$ at 3 years and $-3.0 \%$ versus $3.9 \%$ at 5 years, respectively (Fig. 1b).

\section{Fractures}

At least one fragility fracture was reported by 18 premenopausal and 38 postmenopausal patients. The rate of selfreported fractures did not differ between the exercise and control groups $(p=0.91)$. Patients with a fracture were significantly older than those without ( $p=0.018)$, while MET hours per week, type of endocrine therapy, or results in the figure- 8 running and 2-km walking test were not associated with fracture rate.

\section{Effect of the exercise intervention on total physical activity}

Patients in the control group increased their leisure time physical activity more than women in the exercise intervention group. However, changes in moderate- to hard-intensity physical activity during the 5 years of follow-up did not differ significantly between the exercise and control groups among premenopausal $(p=0.053)$ or postmenopausal $(p=0.159)$ women.

Among premenopausal patients, women in the exercise group maintained their activity level (+0.27 MET-h/week), while those in the control group increased their activity by + 4.0 MET-h/week during the 5-year follow-up. The baseline mean physical activity performed at moderate to hard intensity was 17.40 MET-h/week in the exercise group and 15.30 MET-h/week in the control group. During the intervention year, moderate- to hard-intensity activity increased by +1.19 MET-h/week among women in the exercise group and +1.98 MET-h/week in the controls. During the subsequent 4 years, women in the exercise group decreased their activity by -2.00 MET-h/week, while those in the control group further increased theirs by $+1.74 \mathrm{MET}-\mathrm{h} /$ week. 
Table 1 Baseline characteristics

\begin{tabular}{|c|c|c|c|c|}
\hline \multirow[t]{2}{*}{ Characteristics } & \multicolumn{2}{|l|}{ Premenopausal } & \multicolumn{2}{|l|}{ Postmenopausal } \\
\hline & Exercise $(n=107)$ & Control $(n=94)$ & Exercise $(n=128)$ & Control $(n=115)$ \\
\hline Age, years* (range) & $46.0(36.0-54.3)$ & $46.2(34.7-56.6)$ & $57.4(47.2-67.6)$ & $58.0(45.7-68.2)$ \\
\hline Tumor size, mm** (range) & $18(5-70)$ & $20(4-72)$ & $18(4-100)$ & $20(4-130)$ \\
\hline Metastatic lymph nodes, $n^{* *}$ (range) & $1(0-17)$ & $1(0-42)$ & $1(0-20)$ & $1(0-17)$ \\
\hline Weight, kg* (SD) & $69.5(10.5)$ & $69.6(12.6)$ & $73.1(12.4)$ & $69.5(12.0)$ \\
\hline Height, cm* (SD) & $165.8(6.1)$ & $166.6(6.3)$ & $163.6(5.0)$ & $163.9(5.7)$ \\
\hline BMI, kg/m² (SD) & $25.3(3.7)$ & $25.1(4.5)$ & $27.3(4.3)$ & $25.9(4.2)$ \\
\hline \multicolumn{5}{|l|}{ Helsinki population $(n=346)$} \\
\hline $\mathrm{FN}$ aBMD, $\mathrm{g} / \mathrm{cm}^{2} *(\mathrm{SD})$ & $0.77(0.08)$ & $0.79(0.11)$ & $0.77(0.11)$ & $0.77(0.11)$ \\
\hline $\mathrm{TH}$ aBMD, $\mathrm{g} / \mathrm{cm}^{2} *(\mathrm{SD})$ & $0.90(0.01)$ & $0.94(0.01)$ & $0.93(0.01)$ & $0.93(0.01)$ \\
\hline LS aBMD, $\mathrm{g} / \mathrm{cm}^{2} *(\mathrm{SD})$ & $0.98(0.10)$ & $1.01(0.12)$ & $0.98(0.11)$ & $0.98(0.11)$ \\
\hline \multicolumn{5}{|l|}{ Tampere population $(n=65)$} \\
\hline $\mathrm{FN}$ aBMD, $\mathrm{g} / \mathrm{cm}^{2} *(\mathrm{SD})$ & $0.94(0.08)$ & $0.96(0.07)$ & $0.95(0.15)$ & $0.92(0.12)$ \\
\hline $\mathrm{TH}$ aBMD, $\mathrm{g} / \mathrm{cm}^{2} *(\mathrm{SD})$ & $1.01(0.03)$ & $1.03(0.02)$ & $1.02(0.04)$ & $0.99(0.03)$ \\
\hline LS aBMD, g/cm² ${ }^{2}(\mathrm{SD})$ & $1.15(0.13)$ & $1.15(0.13)$ & $1.14(0.18)$ & $1.11(0.12)$ \\
\hline \multicolumn{5}{|l|}{ Turku population $(n=32)$} \\
\hline $\mathrm{FN}$ aBMD, $\mathrm{g} / \mathrm{cm}^{2} *(\mathrm{SD})$ & $0.78(0.08)$ & $0.85(0.16)$ & $0.77(0.12)$ & $0.80(0.09)$ \\
\hline $\mathrm{TH}$ aBMD, $\mathrm{g} / \mathrm{cm}^{2} *(\mathrm{SD})$ & $0.91(0.03)$ & $0.98(0.09)$ & $0.87(0.04)$ & $0.91(0.04)$ \\
\hline LS aBMD, $\mathrm{g} / \mathrm{cm}^{2} *(\mathrm{SD})$ & $0.97(0.11)$ & $1.13(0.20)$ & $0.97(0.09)$ & $0.93(0.09)$ \\
\hline \multicolumn{5}{|l|}{ Leisure time activity, $n(\%)$} \\
\hline Low & $19(17.8)$ & $14(14.9)$ & $25(19.5)$ & $15(13.0)$ \\
\hline Moderate & $53(49.5)$ & $50(53.2)$ & $68(53.1)$ & $68(59.1)$ \\
\hline High & $32(29.9)$ & $23(24.5)$ & $31(24.2)$ & $28(24.3)$ \\
\hline Missing data & $3(2.8)$ & $7(7.4)$ & $4(3.2)$ & $4(3.6)$ \\
\hline MET-h/week* (SD) & $26.4(14.6)$ & $26.1(15.0)$ & $27.0(18.3)$ & $26.9(17.7)$ \\
\hline Radiotherapy, $n(\%)$ & $85(79.4)$ & $67(71.3)$ & $99(77.3)$ & $94(81.7)$ \\
\hline Chemotherapy, $n(\%)$ & $96(89.7)$ & $86(91.5)$ & $113(88.3)$ & $106(92.2)$ \\
\hline \multicolumn{5}{|l|}{ Endocrine therapy, n (\%) } \\
\hline Tamoxifen & $89(83.2)$ & $68(72.3)$ & $38(29.7)$ & $33(28.7)$ \\
\hline Aromatase inhibitor & $2(1.9)$ & $2(2.1)$ & $67(52.3)$ & $65(56.5)$ \\
\hline Other therapy or missing data & $16(15.0)$ & $24(25.6)$ & $23(17.9)$ & $17(14.8)$ \\
\hline
\end{tabular}

* mean, ** median, $n$ number, $S D$ standard deviation, $B M I$ body mass index, $a B M D$ areal bone mineral density

In postmenopausal patients, women in the exercise group gained only + 0.61 MET-h/week during the 5-year follow-up, while those in the control group increased their activity by + 3.97 MET-h/week. The mean baseline level of moderate- to hard-intensity physical activity was $14.75 \mathrm{MET}-\mathrm{h} /$ week in the exercise group and 12.91 MET-h/week in the control group. During the intervention year, MET-h/week increased both in the exercise (+ 4.76 MET-h/week) and control groups (+ 4.65 MET-h/week). During the subsequent 4 years, women in the exercise group decreased their activity by $-3.76 \mathrm{MET}-\mathrm{h} /$ week, while those in the control group maintained their activity level (-0.24 MET-h/week) (Fig. 2a and Electronic Supplementary Material).

\section{Effect of the exercise intervention on physical performance}

\section{2-km walking test}

In premenopausal women, the walking test performance improved significantly more among women in the exercise group as compared with controls $(p=0.011)$. The $2-\mathrm{km}$ walking test time improved by $-1.26 \mathrm{~min}$ in the exercise and $-0.66 \mathrm{~min}$ in the control group during the 5-year follow-up. The mean baseline 2-km walking time was $18.2 \mathrm{~min}$ in the exercise group and $17.8 \mathrm{~min}$ in the control group. During the intervention year, improvements of -0.98 and $-0.64 \mathrm{~min}$ 
Fig. 1 a Percentage changes of the FN aBMD in the exercise (intervention) and control groups. b Percentage changes of the LS aBMD in the exercise (intervention) and control groups a
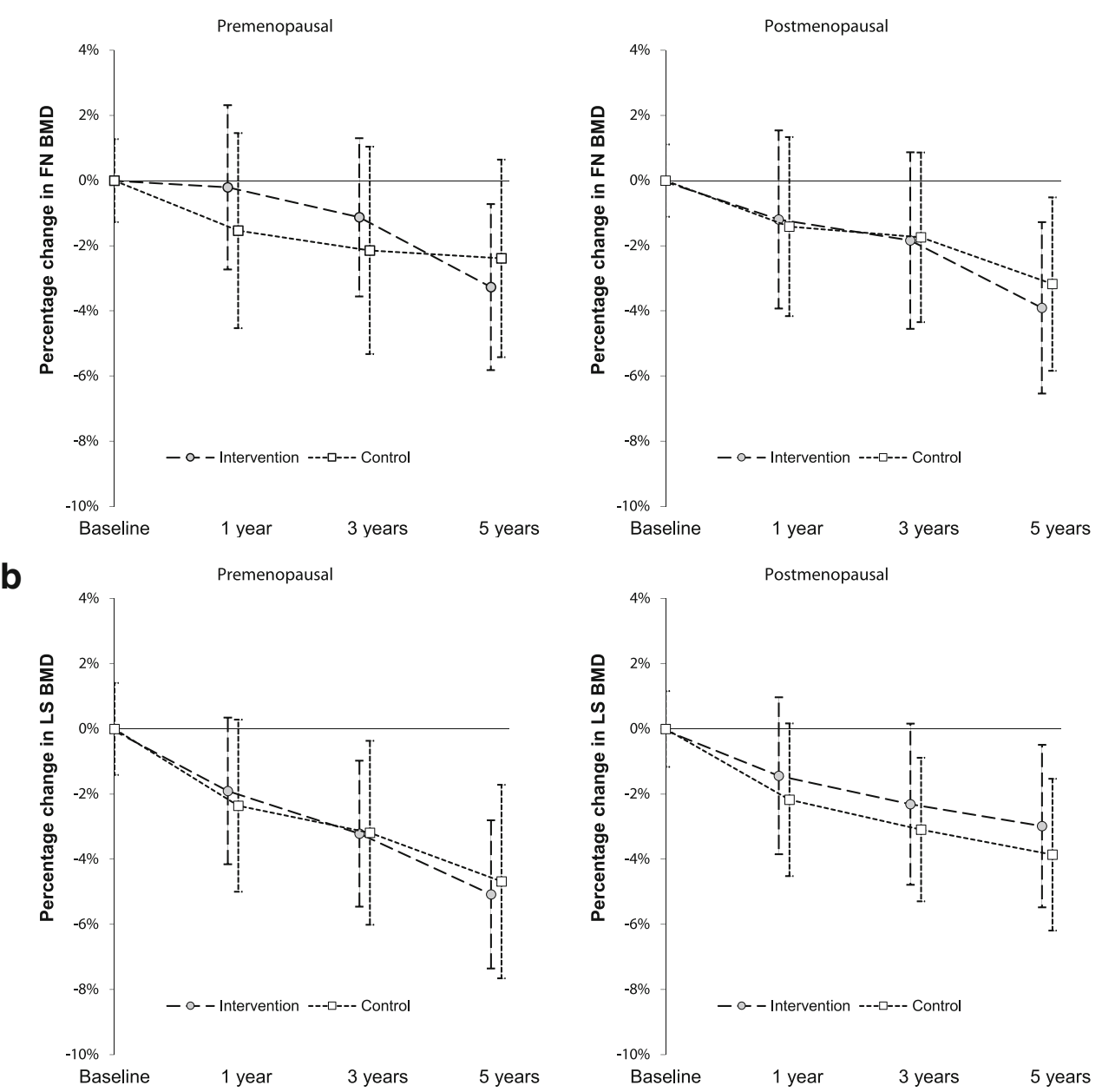

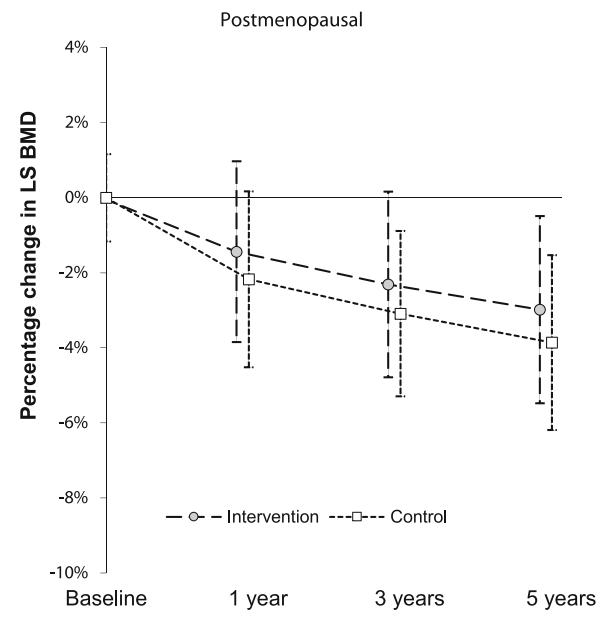

were seen among women in the exercise and control groups, respectively. During the subsequent 4 years, changes in the 2$\mathrm{km}$ walking time were -0.01 and $-0.22 \mathrm{~min}$ in the exercise and control groups, respectively.

The exercise intervention did not significantly affect walking test performance in postmenopausal women $(p=0.253)$. The $2-\mathrm{km}$ walking test time improved by $-0.45 \mathrm{~min}$ in the exercise and -0.70 in the control group. The mean baseline $2-$ $\mathrm{km}$ walking time was $19.2 \mathrm{~min}$ in the exercise group and $18.8 \mathrm{~min}$ among the controls. During the intervention year, improvements of -0.79 and -0.83 min were seen among women in the exercise and control groups, respectively. During the subsequent 4 years follow-up, changes in the 2 $\mathrm{km}$ walking time were +0.37 and $+0.21 \mathrm{~min}$ in the exercise and control groups, respectively (Fig. $2 \mathrm{~b}$ and Electronic Supplementary Material).

\section{Figure-8 running test}

In premenopausal women, the changes in figure- 8 running time improved significantly more among patients in the exercise group as compared with controls $(p=0.006)$. The figure- 8 running time improved by $-0.25 \mathrm{~s}$ in the exercise and $-0.12 \mathrm{~s}$ in the control group during the 5-year follow-up. The baseline mean figure- 8 running time was $15.15 \mathrm{~s}$ in the exercise group and $14.97 \mathrm{~s}$ among the controls. During the exercise intervention, an improvement of $-0.34 \mathrm{~s}$ was seen among women in the exercise group, while the running time increased by $+0.08 \mathrm{~s}$ among those in the control group. During the subsequent 4 years, changes in the figure- 8 running time were +0.08 and $-0.14 \mathrm{~s}$ in the exercise and control groups, respectively.

In postmenopausal women, the changes in figure- 8 running time did not significantly differ between the exercise and control groups $(p=0.379)$. The figure- 8 running time increased by $+0.15 \mathrm{~s}$ in the exercise group and $+0.22 \mathrm{~s}$ in the control group during the 5-year follow-up. The baseline mean figure8 running time was $16.71 \mathrm{~s}$ in the exercise group and $16.63 \mathrm{~s}$ among the controls. During the exercise intervention, an improvement of $-0.24 \mathrm{~s}$ was seen among women in the exercise group, while the running time increased by $+0.06 \mathrm{~s}$ among the controls. During the subsequent 4 years, changes in the figure- 
Fig. 2 a Percentage changes in moderate- to hard-intensity METhours per week. b Percentage changes in time spent walking $2 \mathrm{~km}$ (UKK walking test). c Percentage changes in time spent running figure-8 a
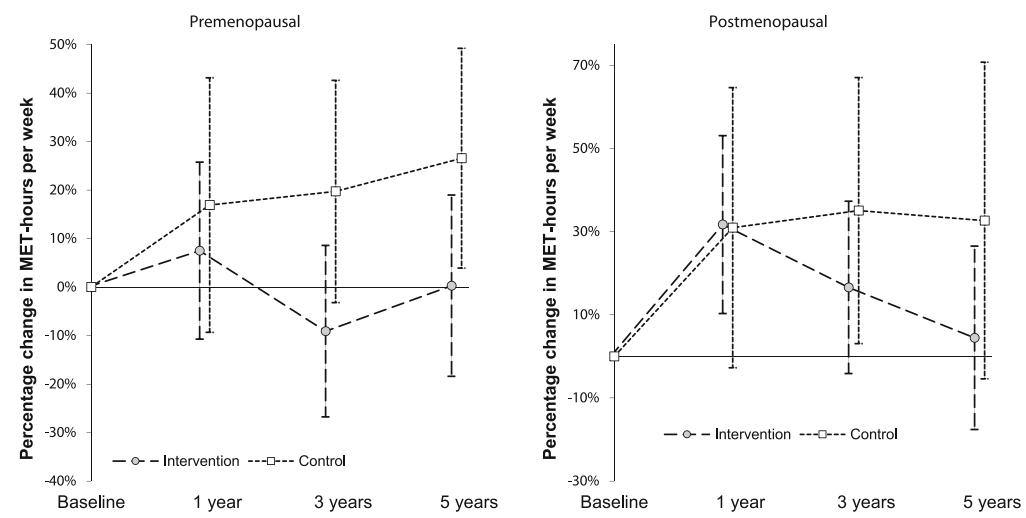

b
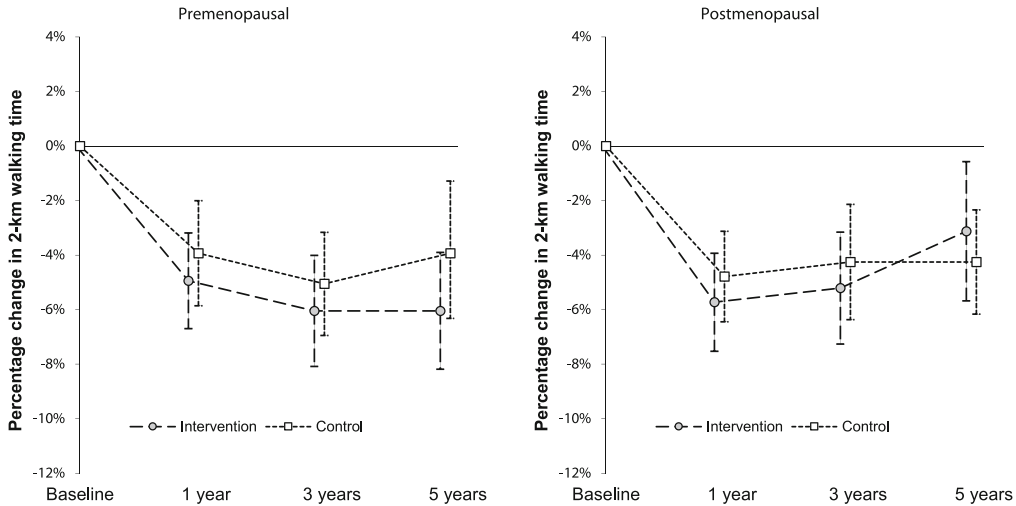

C
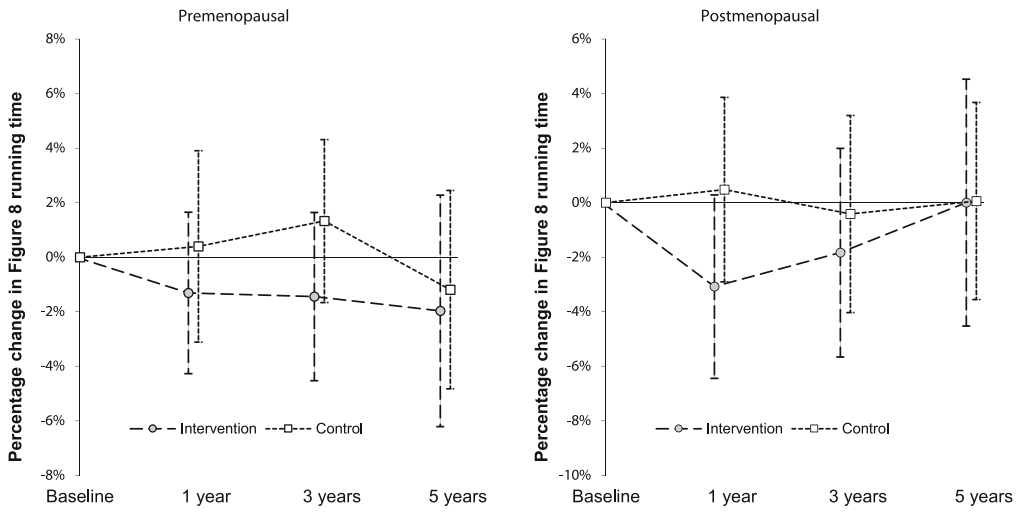

8 running time were +0.32 and $+0.16 \mathrm{~s}$ in the exercise and control groups, respectively (Fig. 2c and Electronic Supplementary Material).

\section{Discussion}

The primary objective of this prospective follow-up of a randomized clinical trial was to evaluate the effect of supervised weight-bearing jumping exercises and circuit training on bone loss among pre- and postmenopausal breast cancer patients. The 12-month exercise intervention prevented $\mathrm{FN}$ and $\mathrm{TH}$ bone loss in premenopausal patients during the intervention. The bone-protective effect was still evident 2 years after completion of the intervention, but was lost during further followup. LS bone loss was not prevented by the exercise program in premenopausal women and no effect on aBMD at any site was seen among postmenopausal women.

Exercise intervention improved the cardiorespiratory fitness assessed by $2-\mathrm{km}$ walking test and dynamic neuromuscular performance evaluated by 8-figure running test in premenopausal patients. This was true despite the fact that the intervention had no significant effect on the total amount of leisure time physical activity. On the contrary, the control patients were actually more 
physically active than patients in the intervention group after the end of the 1-year exercise program.

In line with the previous literature, premenopausal women were more responsive to bone-protective effects of exercise than postmenopausal women [28-30]. In the present study, premenopausal women in the intervention group were able to improve their physical performance, while no improvement was seen among postmenopausal women as compared with controls. Improved physical and neuromuscular performance may translate into more intensive movements and higher ground impacts that are characteristic to osteogenic physical loading [14].

Improved physical performance might, at least partly, explain the difference in aBMD effects between pre- and postmenopausal women as better physical performance facilitates more intensive training. In a previous study, high-impact jumping exercise was found beneficial both at the FN and the LS aBMD among healthy premenopausal women [31]. This exercise-induced aBMD gain was maintained for at least 3.5 years at the FN [32]. However, weight-bearing jumping exercise had no effect on bone mass among healthy early postmenopausal women despite beneficial training effects on physical performance [33].

A recent meta-analysis on the aBMD effects of exercise among breast and prostate cancer survivors $(n=814)$ comprising six RCTs and including the current BREX showed a trend for an exercise-induced aBMD benefit both at the LS $(p=0.057)$ and at the FN $(p=0.077)$. Subgroup analysis revealed a significant positive training effect on LS aBMD in three studies implementing a combined resistance and impact exercise intervention [30]. This underscores the importance of considering the type and intensity, not only the amount of exercise, in studies evaluating the effects of training on aBMD.

Somewhat surprisingly, women in the control group increased their total leisure time physical activity more than women in the exercise group. The fact that femoral bone loss among premenopausal women was reduced during the intervention period despite a physically more active control group underscores the importance of exercise type (here the impact loading) and not only the total amount of physical activity in prevention of osteoporosis. It seems that after the 1-year exercise intervention stopped, patients in the exercise group lost their interest in extra training, whereas women in the control group had chosen their preferred mode of physical exercise more freely and were thus more motivated to keep up with extra training in the long run. Perhaps an individualized exercise program according to patient's preferences and exercise habits before cancer diagnosis could better support permanent lifestyle changes than a structured intervention. The ultimate challenge in all exercise interventions is how to maintain the participants' long-term adherence to physically active lifestyle.
Bisphosphonates and denosumab are effective against cancer treatment-related bone loss and reduce the risk of fracture in patients with early breast cancer. In addition, bisphosphonates decrease the risk of bone metastases and breast cancer death among postmenopausal women $(1,6,7)$. On the contrary, in young premenopausal women bisphosphonates may be associated with an increase in relapse risk and a worse overall survival [34]. Since bisphosphonates are not without risk in young women, exercise could provide a safe and natural means to preserve bone mass in premenopausal women with early breast cancer.

In addition to its bone-protective potential, exercise has multiple other health benefits like improved muscle strength, balance and coordination, better cardiorespiratory fitness, as well as lower risk of fall-related injuries and many other diseases affecting public health $[35,36]$. Among cancer survivors, exercise helps to combat treatment-related adverse effects like fatigue and even a positive effect on breast cancer prognosis has been suggested [8-10]. Thus, regular exercise can be recommended not only to protect the bone but also to improve the general health and quality of life of cancer patients. Future studies are needed to explore what kind of exercise would be most feasible and effective to improve cardiovascular and neuromuscular fitness and to prevent treatmentrelated adverse effects like bone loss.

The current BREX study is, to our knowledge, the largest randomized exercise intervention trial in breast cancer survivors. The relatively intensive exercise program selected was pretested for feasibility in breast cancer patients and found effective in bone protection [37]. The large sample size and long follow-up time are among the strengths of BREX. The main confounding element of the study was the unexpected rise in physical activity among patients in the control group. This compromised our ability to detect the overall exercise effect on aBMD by comparing the two randomized groups. On the other hand, the fact that the exercise program in the present study did prevent aBMD loss at the FN and TH despite activation of the control group confirms the fact that different types of physical activity have different effects on aBMD [38]. The physical activity measure used in the current study may not be the most appropriate to quantify bone-relevant loading, as, for instance, swimming may contribute a large number of MET-h but not stimulate much bone adaptation.

In conclusion, our 12-month exercise program improved physical performance and prevented femoral bone loss in premenopausal breast cancer patients during the intervention. The bone-protective effect was still evident 2 years after the end of the intervention despite the reduced overall physical activity of women in the exercise group, but was lost thereafter. Our findings emphasize the fact that premenopausal women are more responsive to bone-protective effects of exercise than postmenopausal women. 
Funding Open access funding provided by University of Helsinki including Helsinki University Central Hospital. The study has been financially supported by the Cancer Society of Finland, the Finnish Cancer Foundation, the Academy of Finland, the Comprehensive Cancer Center Helsinki University Central Hospital, the Social Insurance Institution of Finland, the Finnish Ministry of Education, Finska Läkaresällskapet, the Special Government Grant for Health Science Research, the Helander Foundation, the Paulo Foundation, Finnish Cultural Foundation, and Medical Fund of the Pirkanmaa Hospital District. Finnish Astra-Zeneca sponsored step benches for the study. The study was sponsored by The Finnish Breast Cancer group.

\section{Compliance with ethical standards}

All procedures performed in studies involving human participants were in accordance with the ethical standards of the institutional and/or national research committee and with the 1964 Helsinki declaration and its later amendments or comparable ethical standards.

Conflicts of interest Leena Vehmanen, Meri Utriainen, Carl Blomqvist, Tiina Saarto, Harri Sievänen, Kari Tokola, Pirkko Kellokumpu-Lehtinen, Riku Nikander, Riikka Huovinen, Johanna Ruohola and Heidi M. Penttinen declare that they have no conflict of interest.

Open Access This article is licensed under a Creative Commons Attribution-NonCommercial 4.0 International License, which permits any non-commercial use, sharing, adaptation, distribution and reproduction in any medium or format, as long as you give appropriate credit to the original author(s) and the source, provide a link to the Creative Commons licence, and indicate if changes were made. The images or other third party material in this article are included in the article's Creative Commons licence, unless indicated otherwise in a credit line to the material. If material is not included in the article's Creative Commons licence and your intended use is not permitted by statutory regulation or exceeds the permitted use, you will need to obtain permission directly from the copyright holder. To view a copy of this licence, visit http://creativecommons.org/licenses/by-nc/4.0/.

\section{References}

1. Hajdi P, Aapro M, Body J et al (2017) Management of aromatase inhibitor associated bone loss (AIBL) in postmenopausal women with hormone sensitive breast cancer. Joint position statement of IOF, CABS, ECTS, IEG, ESCEO, IMS and SIOG. J Bone Oncol 7: 1-12. https://doi.org/10.1016/j.jbo.2017.03.001

2. Chen Z, Maricic M, Bassford TL, Pettinger M, Ritenbaugh C, Lopez AM, Barad DH, Gass M, Leboff MS (2005) Fracture risk among breast cancer survivors: results from the Women's Health Initiative Observational Study. Arch Intern Med 165:552-558. https://doi.org/10.1001/archinte.165.5.552

3. Shapiro CL, Manola J, Leboff M (2001) Ovarian failure after adjuvant chemotherapy is associated with rapid bone loss in women with early-stage breast cancer. J Clin Oncol 19:3306-3311. https://doi.org/10.1200/JCO.2001.19.14.3306

4. Saarto T, Blomqvist C, Välimäki M, Mäkelä P, Sarna S, Elomaa I (1997) Chemical castration induced by adjuvant cyclophosphamide, methotrexate, and fluorouracil chemotherapy causes rapid bone loss that is reduced by clodronate: a randomized study in premenopausal breast cancer patients. J Clin Oncol 15:13411347. https://doi.org/10.1200/JCO.1997.15.4.1341

5. Perez E, Josse RG, Pritchard KI et al (2006) Effect of letrozole versus placebo on bone mineral density in women with primary breast cancer completing 5 or more years of adjuvant tamoxifen: a companion study to NCIC CTG MA.17. J Clin Oncol 24:36293635. https://doi.org/10.1200/JCO.2005.05.4882

6. Dhesy-Thind S, Fletcher G, Blanchette P et al (2017) Use of adjuvant bisphosphonates and other bone-modifying agents in breast cancer: a Cancer Care Ontario and American Society of Clinical Oncology Clinical Practice Guideline. J Clin Oncol 35:2062-2081. https://doi.org/10.1200/JCO.2016.70.7257

7. Early Breast Cancer Trialists' Collaborative Group (EBCTCG) (2015) Adjuvant bisphosphonate treatment in early breast cancer: meta-analyses of individual patient data from randomized trials. Lancet 386:1353-1361. https://doi.org/10.1016/S0140-6736(15) 60908-4

8. Saarto T, Penttinen HM, Sievänen H et al (2012) Effectiveness of a 12-month exercise program on physical performance and quality of life of breast cancer survivors. Anticancer Res 32:3875-3884

9. Loprinzi PD, Cardinal BJ (2012) Effects of physical activity on common side effects of breast cancer treatment. Breast Cancer 19: 4-10. https://doi.org/10.1007/s12282-011-0292-3

10. Schmid D, Leitzmann MF (2014) Association between physical activity and mortality among breast cancer and colorectal cancer survivors: a systematic review and meta-analysis. Ann Oncol 25: 1293-1311. https://doi.org/10.1093/annonc/mdu012

11. Wolff I, van Croonenborg JJ, Kemper HC et al (1999) The effect of exercise training programs on bone mass: a meta-analysis of published controlled trials in pre- and postmenopausal women. Osteoporos Int 9:1-12. https://doi.org/10.1007/s001980050109

12. Kelley GA, Kelley KS, Kohrt WM (2013) Exercise and bone mineral density in premenopausal women: a meta-analysis of randomized controlled trials. Int J Endocrinol 2013:741-639. https://doi. org/10.1155/2013/741639

13. Zhao R, Zhao M, Xu Z (2015) The effects of differing resistance training modes on the preservation of bone mineral density in postmenopausal women: a meta-analysis. Osteoporos Int 26:16051618. https://doi.org/10.1007/s00198-015-3034-0

14. Nikander R, Sievänen H, Heinonen A, Daly RM, Uusi-Rasi K, Kannus P (2010) Targeted exercise against osteoporosis: a systematic review and meta-analysis for optimising bone strength throughout life. BMC Med 8:47. https://doi.org/10.1186/1741-7015-8-47

15. Thomas GA, Cartmel B, Harrigan M, Fiellin M, Capozza S, Zhou Y, Ercolano E, Gross CP, Hershman D, Ligibel J, Schmitz K, Li FY, Sanft T, Irwin ML (2017) The effect of exercise on body composition and bone mineral density in breast cancer survivors taking aromatase inhibitors. Obesity 25:346-351. https://doi.org/ 10.1002/oby.21729

16. Kim SH, Cho YU, Kim SJ, Hong S, Han MS, Choi E (2016) The effect on bone outcomes of adding exercise to supplements for osteopenic breast cancer survivors: a pilot randomized controlled trial. Cancer Nurs 39:144-152. https://doi.org/10.1097/NCC. 0000000000000245

17. Knobf MT, Jeon S, Smith B, Harris L, Kerstetter J, Thompson AS, Insogna K (2016) Effect of a randomized controlled exercise trial on bone outcomes: influence of adjuvant endocrine therapy. Breast Cancer Res Treat 155:491-500. https://doi.org/10.1007/s10549016-3693-3

18. Winters-Stone KM, Dobek J, Nail L, Bennett JA, Leo MC, Naik A, Schwartz A (2011) Strength training stops bone loss and builds muscle in postmenopausal breast cancer survivors: a randomized, controlled trial. Breast Cancer Res Treat 127:447-456. https://doi. org/10.1007/s10549-011-1444-z

19. Winters-Stone KM, Dobek J, Nail LM, Bennett JA, Leo MC, Torgrimson-Ojerio B, Luoh SW, Schwartz A (2013) Impact + resistance training improves bone health and body composition in prematurely menopausal breast cancer survivors: a randomized controlled trial. Osteoporos Int 24:1637-1646. https://doi.org/10. 1007/s00198-012-2143-2 
20. Winters-Stone KM, Laudermilk M, Woo K, Brown JC, Schmitz KH (2014) Influence of weight training on skeletal health of breast cancer survivors with or at risk for breast cancer-related lymphedema. J Cancer Surviv 8:260-268. https://doi.org/10.1007/s11764013-0337-z

21. Schwartz AL, Winters-Stone K, Gallucci B (2007) Exercise effects on bone mineral density in women with breast cancer receiving adjuvant chemotherapy. Oncol Nurs Forum 34:627-633. https:// doi.org/10.1188/07.ONF.627-633

22. Waltman NL, Twiss JJ, Ott CD, Gross GJ, Lindsey AM, Moore TE, Berg K, Kupzyk K (2010) The effect of weight training on bone mineral density and bone turnover in postmenopausal breast cancer survivors with bone loss: a 24-month randomized controlled trial. Osteoporos Int 21:1361-1369. https://doi.org/10.1007/s00198009-1083-y

23. Irwin ML, Alvarez-Reeves M, Cadmus L, Mierzejewski E, Mayne ST, Yu H, Chung GG, Jones B, Knobf MT, DiPietro L (2009) Exercise improves body fat, lean mass, and bone mass in breast cancer survivors. Obesity 17:1534-1541. https://doi.org/10.1038/ oby. 2009.18

24. Saarto T, Sievänen H, Kellokumpu-Lehtinen P, Nikander R, Vehmanen L, Huovinen R, Kautiainen H, Järvenpää S, Penttinen HM, Utriainen M, Jääskeläinen AS, Elme A, Ruohola J, Palva T, Vertio H, Rautalahti M, Fogelholm M, Luoto R, Blomqvist C (2012) Effect of supervised and home exercise training on bone mineral density among breast cancer patients. A 12-month randomized controlled trial. Osteoporos Int 23:1601-1612. https://doi.org/ 10.1007/s00198-011-1761-4

25. Ainsworth BE, Haskell WL, Whitt MC et al (2000) Compendium of physical activities: an update of activity codes and MET intensities. Med Sci Sports Exerc 32:498-504. https://doi.org/10.1097/ 00005768-200009001-00009

26. Oja P, Laukkanen R, Pasanen M, Tyry T, Vuori I (1991) A 2-km walking test for assessing the cardiorespiratory fitness of healthy adults. Int J Sports Med 12:356-362. https://doi.org/10.1055/s2007-1024694

27. Tegner Y, Lysholm J, Lysholm M, Gillquist J (1986) A performance test to monitor rehabilitation and evaluate anterior cruciate ligament injuries. Am J Sports Med 14:156-159. https://doi.org/10. 1177/036354658601400212

28. Bassey E, Rothwell M, Littlewood J, Pye D (1998) Pre- and postmenopausal women have different bone mineral density responses to the same high-impact exercise. J Bone Miner Res 13:1805-1813. https://doi.org/10.1359/jbmr.1998.13.12.1805

29. Sugiyama T, Yamaguchi A, Kawai S (2002) Effects of skeletal loading on bone mass and compensation mechanism in bone: a new insight into the B mechanostat theory. J Bone Miner Metab 20:196-200. https://doi.org/10.1007/s007740200028

30. Dalla via J, Daly RM, Fraser SF (2018) The effect of exercise on bone mineral density in adult cancer survivors: a systematic review and meta-analysis. Osteoporosis Int 29:287-303. https://doi.org/10. 1007/s00198-017-4237-3

31. Heinonen A, Kannus P, Sievänen H, Oja P, Pasanen M, Rinne M, Uusi-Rasi K, Vuori I (1996) Randomised controlled trial of effect of high-impact exercise on selected risk factors for osteoporotic fractures. Lancet 348:1343-1347. https://doi.org/10.1016/S01406736(96)04214-6

32. Kontulainen S, Heinonen A, Kannus P et al (2004) Former exercisers of an 18-month intervention display residual aBMD benefits compared with control women 3.5 years post-intervention: a follow-up of a randomized controlled high-impact trial. Osteoporos Int 15:248-251. https://doi.org/10.1007/s00198-003$1559-0$

33. Uusi-Rasi K, Kannus P, Cheng S, Sievänen H, Pasanen M, Heinonen A, Nenonen A, Halleen J, Fuerst T, Genant H, Vuori I (2003) Effect of alendronate and exercise on bone and physical performance of postmenopausal women: a randomized controlled trial. Bone 33:132-143. https://doi.org/10.1016/s8756-3282(03) 00082-6

34. Coleman R, Collinson M, Gregory W et al (2018) Benefits and risks of adjuvant treatment with zoledronic acid in stage II/III breast cancer. 10 years follow-up of the AZURE randomized clinical trial (BIG 01/04). Bone Oncol 13:123-135. https://doi.org/10.1016/j. jbo.2018.09.008

35. Willis B, Gao A, Leonard D et al (2012) Midlife fitness and the development of chronic conditions in later life. Arch Intern Med 172:1333-1340. https://doi.org/10.1001/archinternmed.2012.3400

36. Piercy K, Troiano R, Ballard R et al (2018) The physical activity guidelines for Americans. JAMA 320:2020-2028. https://doi.org/ 10.1001/jama.2018.14854

37. Nikander R, Sievänen H, Ojala K, Oivanen T, KellokumpuLehtinen PL, Saarto T (2007) Effect of a vigorous aerobic regimen on physical performance in breast cancer patients - a randomized controlled pilot trial. Acta Oncol 46:181-186. https://doi.org/10. 1080/02841860600833145

38. Nikander R, Kannus P, Dastidar P et al (2009) Targeted exercises against hip fragility. Osteoporos Int 20:1321-1328. https://doi.org/ 10.1007/s00198-008-0785-x

Publisher's note Springer Nature remains neutral with regard to jurisdictional claims in published maps and institutional affiliations. 